\title{
Standard Drafting Unit Evaluation Model Comparative Study
}

\author{
Yunpeng Chen ${ }^{1, a^{*}}$, Yan $\mathrm{Gao}^{2, \mathrm{~b}}$, Jingjing $\mathrm{Han}^{3, \mathrm{c}}$ and Sihan $\mathrm{Liu}^{4, \mathrm{~d}}$ \\ ${ }^{1,2}$ Chinese Standardization Research Institute, Haidian, Beijing, China, 100191 \\ ${ }^{3}$ Communication University of China, Chaoyang, Beijing, China, 100024 \\ achenyp@cnis.gov.cn, bgaoyan@cnis.gov.cn, chanjingjing24@126.com, d958801185@qq.com
}

Keywords: The drafting unit; Multivariate statistical analysis; Systems engineering evaluation method; The evaluation method of operational research; Intelligent evaluation method

\begin{abstract}
Standard between the countries all over the world and domestic trade plays an important role to rent, mainly by the international, regional, national and state the following levels of organization. In the era of big data, data as the foundation of support from all walks of life decisions, based on analysis of large data index concept is hot. How to go from standard draft Angle to the establishment of a unified evaluation index, the application of the concept of index in the evaluation and measure standards drafting unit of is of great significance. This project is to standard drafting unit as the research object, research evaluation index system for the construction of the standard drafting unit, statistical analysis and related design and implementation of the algorithm. This report data from supported by ministry of science and technology and the ministry of finance, general administration of quality supervision, inspection and quarantine and national standard committee of management, China academy of standardized national standard library is responsible for the construction operation of the "national standards literature sharing service platform". This report involves published in 2016, 1763 national standards for detailed data, the standard drafting units distributed in all over the country provinces and autonomous regions, a total of 5475 units. According to the national standard index distribution, this report based on drafting unit of the national standard by the index analysis and ranking analysis of two parts.
\end{abstract}

\section{Introduction}

The standard plays an important role in the trade and trade between countries of the world and within the country, mainly by the international, regional, national and national institutions.

The standard is a summary of scientific, technical and practical experiences. To get the best order in a certain scope, the actual or potential problem set common and repeated use of the rules of the activity, namely the formulation of standards, release and implementation process, known as standardization. The standard formulation and type shall be divided into international standards, regional standards, national standards, professional standards, local standards and enterprise standards according to the scope of use.

It is very important for the national standard to draft the comprehensive strength of product quality, technology, innovation and other indicators in the industry. To some extent, by the contribution index to measure the drafting unit's contribution to the standard and is important in the standard drafting to guide and encourage the evaluation object in the right direction and goal development has an important guiding role.

In the era of big data, data has become the basis for the decision-making of various industries, and the index concept based on big data analysis is hot. How to construct a set of unified evaluation index from the standard drafting Angle is of great significance to apply the concept of the index to the evaluation and measurement of the standard drafting unit.

National standard and national standard system revision program evaluation refers to the technology from a standard or project level, coordination of sex of content, the level of structure, application and effect by multiple aspects to carry out the evaluation, and make for the standard or standard program 
what kind of measures should be taken. National standard or project evaluation is the key link in the national standard cleaning work.

With the continuous development of the standard industry in our country, the problems existing in the standard, backward and standards of the technical level of the concentrated expression as the standard system revision, the lagging behind of restricting the development of our country's economy and science and technology, so urgent need for our standard to evaluate and positioning. In 2005, the Chinese institute of standardization Ren Guanhua applicability for national standards such as studied the present situation investigation and analysis, established the standard applicability evaluation index system, as shown in figure 1, the purpose is to clean and build a new type of standard system in our country.

Write summary words associated with the paper topics (such as: to study the importance of each evaluation index/model, and the function of comparative study. Make appropriate modification) in this section is the current standard of standard evaluation system focused on the content and applicability of the evaluation, the standard drafting unit contribution to research or a blank. How to evaluate the standard contribution of standard drafting unit scientifically and effectively is one of the decisive factors for enterprises and institutions to raise standard consciousness and raise standard technical level. Therefore, this research proposes the concept of standard contribution index, through the contribution index to measure the contribution to the standard drafting unit, to guide and encourage the evaluation object in the right direction and goal development has an important guiding role. 


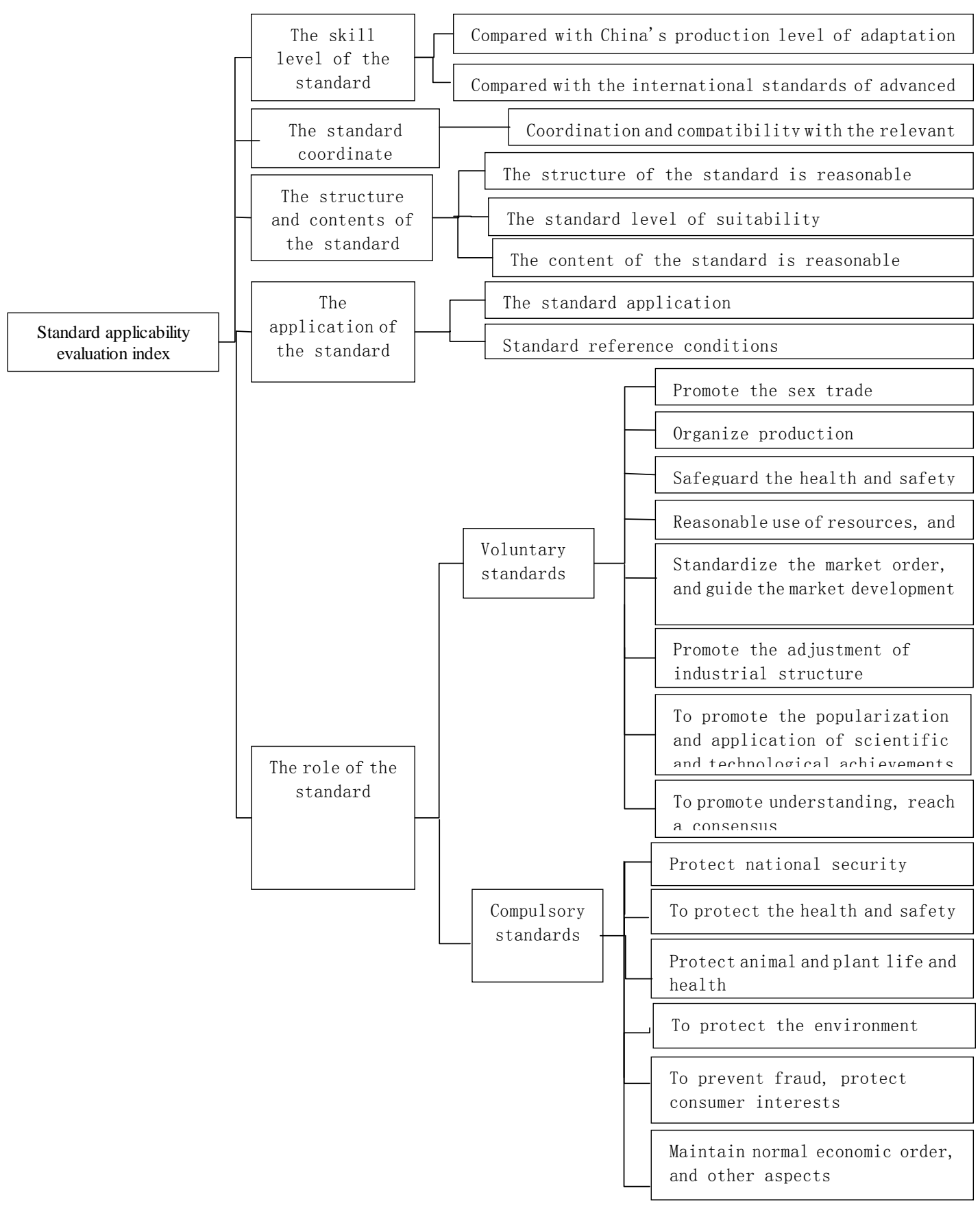

Figure 1. Standard applicability evaluation index system block diagram 


\section{The evaluation index system and index}

The standard evaluation index system.

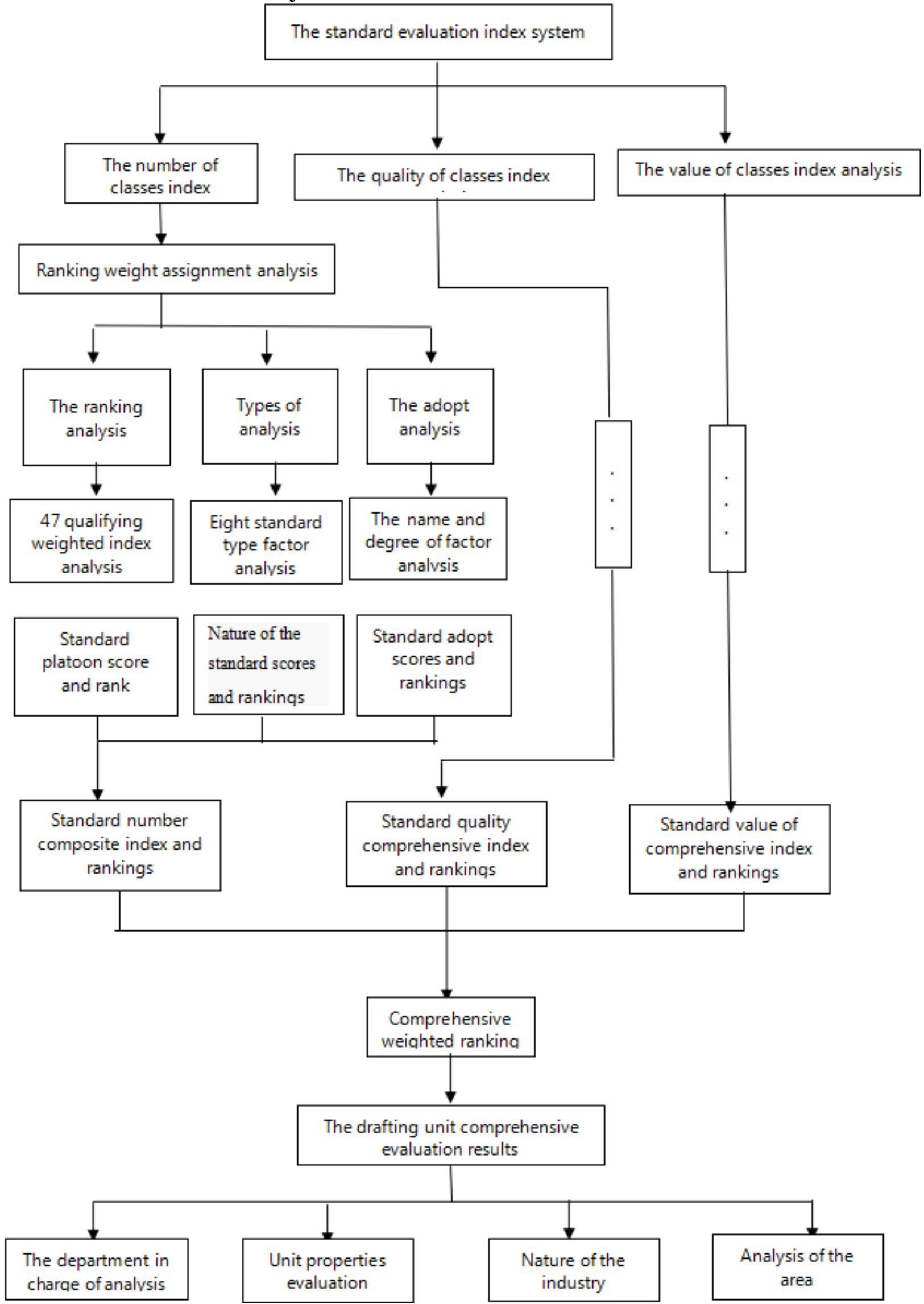

Figure 2. Standard evaluation index system block diagram 


\section{The concept and application of index}

Index refers to the comprehensive, superposition of multiple data sampling, digital statistics work. Index compiled from changes in the price, in Europe in the middle of the 18th century, due to soaring prices cause social unrest, reflect the price change of price index was the result. Index is a comparative statistical indicators, usually is the phenomenon of different time (or space) level comparison, it shows that the phenomenon of changes in time (or space), in the form of a percentage.

The concept of the index is used in every industry, social is closely related with People's Daily lives, investment activities, become a barometer of social economy and life.

In the academic field, in 2005 the university of California, San Diego, physicist George hirsch puts forward $\mathrm{H}$ index, the researchers used to assess academic output quantity and academic level of output, the greater the index shows that the greater the academic influence of the researchers. $\mathrm{H}$ index is a method of quantitative evaluation. Defined as, the researchers in a paper published in a certain time period of at least $h$ article cited frequency of no less than once $h$.

To sum up, the index according to different research purposes and requirements, can be classified as follows:

\section{The individual index and the total index}

The scope of index as the research object, can be divided into individual and total index. Individual index reflects a certain social economic phenomenon individual changes things. Such as reflect the situation of a certain commodity prices change. Total index, comprehensive reflection something changes in the overall situation, including several individual things such as reflect some change in the overall price of commodities. Sometimes in order to research needs, in between the individual and total index, also prepare the group index (or index). Group of establishment method and the total index the same index.

\section{Quantity index and quality index}

The characteristics of the index, in accordance with the said is different, can be divided into quantitative index and quality index index. Quantitative index index reflect the phenomenon of changes in the scale and level of the overall situation, such as production index, index of the staff, etc. Quality indicator index reflects the phenomenon of changes in the connotation of the overall quality, such as commodity price index, labor productivity index, etc.

\section{The dynamic and static index}

Index according to its original meaning, is refers to the dynamic index. But in the process of practical application, meaning gradually extended to static objects and spatial contrast, creating a static index. Static index refers to the at the same time under the condition of different units, different regions, quantity index which is formed by the comparison between the same thing. Or the same unit, in the same area plan index compared with actual value of the index.

\section{Fixed base index and index rose}

Index according to the base used in the index series is different, can be divided into fixed base index and index rose. Fixed base index of a period in sequence with a fixed level compare the benchmark index; Link index is the level of the previous period as compared to the benchmark index.

According to the research purpose and requirements, this study will be comprehensive consideration the quantity index and quality index, in a standard drafting unit as the research object, from the above different Angle to construct the contribution index.

\section{The comparative analysis model method}

Comprehensive evaluation is often used to sort of all the evaluation units, or on the basis of classification of various small classes according to the order. Constitute a comprehensive evaluation problem of five elements are: evaluation objects, evaluation index, weight coefficient, evaluation model and the evaluators.

By evaluation objects,

In this article, by evaluation object is the standard drafting unit.

The evaluation index, 
Evaluation index is reflect the basic requirement of operation condition of the evaluation objects. Evaluation usually consists of a number of indicators, each indicators from different aspects to depict the characteristics of evaluation objects. Evaluation index system is the basis of comprehensive evaluation, the evaluation index system shall comply with the systematic, scientific, comparable, measurability and independence principle. Normally, need to pretreatment of evaluation indexes, including consistent, the dimensionless. The commonly used evaluation index selection method with system analysis method, literature analysis method.

Weight coefficient,

According to the importance of evaluation index is different, its weight coefficient is different. When the evaluation objects and the evaluation index to determine, after the evaluation results will depend on the weight coefficient. Methods to determine the weighing values of including subjective empower and objective empower two kinds big. Objective empowerment from indicators of statistical properties, is determined by the objective data, including fuzzy weighting method, rank, and analogy method, entropy weight method and the correlation coefficient method. Subjective empowerment has the Delphi method (experts), adjacent index comparison method, analytic hierarchy process (AHP) method, etc.

Evaluation model,

Different index system appropriate USES different evaluation model, for example, linear weighted synthesis method is suitable for the situation of each evaluation index are independent of each other nonlinear weighted synthesis method is suitable for the situation of strong correlation between indicators. The commonly used method to calculate the integrated evaluation including arithmetic average method, the geometric average method, mixed synthesis. Among them, the weighted arithmetic mean method of each index can compensate each other, is suitable for the appraisal of prominent main factors; Geometric average law by encouraging evaluation objects in various indicators on the comprehensive development.

Evaluators

Usually, by the evaluators evaluation purpose, evaluation index system, evaluation model and the choice of weight coefficient. 
Table 1 Different categories evaluation method

\begin{tabular}{|c|c|c|c|}
\hline & advantages & disadvantages & Evaluation method \\
\hline $\begin{array}{c}\text { Multivariate } \\
\text { statistical analysis }\end{array}$ & $\begin{array}{l}\text { Don't need } \\
\text { structure weight }\end{array}$ & $\begin{array}{l}\text { The relativity of } \\
\text { the evaluation } \\
\text { conclusion }\end{array}$ & $\begin{array}{l}\text { 1、 the principal component } \\
\text { analysis } \\
\text { 2、 factor analysis }\end{array}$ \\
\hline $\begin{array}{l}\text { Systems } \\
\text { engineering } \\
\text { evaluation } \\
\text { method }\end{array}$ & $\begin{array}{l}\text { Simple easy to } \\
\text { operate }\end{array}$ & $\begin{array}{l}\text { Can only be used } \\
\text { for the static } \\
\text { evaluation and } \\
\text { evaluation object } \\
\text { factor cannot too } \\
\text { much }\end{array}$ & $\begin{array}{l}\text { 1、 the AHP evaluation } \\
\text { method } \\
\text { 2、 Topsis evaluation } \\
\text { method } \\
\text { 3、 the fuzzy evaluation } \\
\text { method } \\
\text { 4、 grey correlation } \\
\text { analysis method } \\
\text { 5、 evaluation based on } \\
\text { rough set theory }\end{array}$ \\
\hline $\begin{array}{l}\text { The evaluation } \\
\text { method of } \\
\text { operational } \\
\text { research }\end{array}$ & $\begin{array}{l}\text { Evaluate multiple } \\
\text { input multiple } \\
\text { output system }\end{array}$ & $\begin{array}{l}\text { Subject to the } \\
\text { conditions of } \\
\text { application } \\
\text { conditions }\end{array}$ & $\begin{array}{l}\text { 1、 the linear } \\
\text { programming } \\
\text { 2、 the dynamic } \\
\text { programming }\end{array}$ \\
\hline $\begin{array}{l}\text { Intelligent } \\
\text { evaluation } \\
\text { method }\end{array}$ & $\begin{array}{l}\text { Has the adaptive } \\
\text { ability }\end{array}$ & $\begin{array}{l}\text { Accuracy is not } \\
\text { high, need a large } \\
\text { number of } \\
\text { training samples }\end{array}$ & $\begin{array}{l}\text { 1、 the artificial neural } \\
\text { network } \\
\text { 2、 the genetic algorithm }\end{array}$ \\
\hline
\end{tabular}

Factor analysis. Factor analysis refers to the study of common factors extracted from the variable group of statistical techniques. The first by a British psychologist Charles e. spearman proposed. He found that the students there was a correlation between two subjects, the result good students, often better perform better in other departments, to speculate whether there is some potential common factor, or say some general intelligence conditions affecting students' academic performance. Factor analysis can find hidden in many variable factors of representative. The same variable in the nature of a factor, can reduce the number of variables, but also test the hypothesis that relationships between variables.

Analytic hierarchy process (AHP). AHP operational research by the United States, Thomas 1. Saaty in the early $1970 \mathrm{~s}$, used to solve complex problems sorting and the defects existing in traditional subjective weighting method. The method by means of single layer analysis, the general goal of continuity decomposition of evaluation objects, through comparing the two to determine the index weight of each layer, and with the aim of the bottom combination weights fixed weight, weighted and composite index, according to the size of the comprehensive index to assess the target.

The section headings are in boldface capital and lowercase letters. Second level headings are typed as part of the succeeding paragraph (like the subsection heading of this paragraph).

TOPSIS (Technique for order preference by similarity to ideal solution, Close to the ideal solution sorting method). Similarity and ideal solution sequence optimization technology, it is based on the normalized after the original data matrix, find the optimal solution and the worst in this limited solution scheme of distance, get the evaluated object and the optimal scheme of distance, get the evaluation objects and degree of relatively close to the optimal solution, as the basis of evaluation of quality in turn. TOPSIS is applicable to the less index number and the object, used in department of the overall evaluation and benefit evaluation, etc.

RSR Comprehensive evaluation method (Rank-sum ratio, Rank and analogy method). RSR by China's statisticians Tian Feng professor in 1998, is a kind of statistical parameters and nonparametric statistical method of combining the. It is based on nonparametric method, by the transformation of the 
index number, number of clusters as a rank, again using the parameter analysis of concept and method research the distribution of RSR, solve the problem of multi-index comprehensive evaluation. Rank and ratio method is suitable for outliers or 0 index, can be used for the statistical prediction, factors and correlation analysis, differential classification and decision analysis, etc. Compare the above evaluation method is as follows:

Table 2 Different evaluation methods

\begin{tabular}{|c|c|c|}
\hline Method & advantages & disadvantages \\
\hline $\begin{array}{l}\text { Multivariat } \\
\text { e statistical } \\
\text { analysis }\end{array}$ & & \\
\hline AHP & $\begin{array}{l}\text { 1. The layered, determining the } \\
\text { weight with combination } \\
\text { weighting comprehensive index, } \\
\text { reduce the deviation of traditional } \\
\text { subjective weighting exist } \\
\text { 2. The practice is not easy to } \\
\text { measure the quantitative target for } \\
\text { easy measurement indicators, not } \\
\text { weaken the original information } \\
\text { 3. Not only can be used in the } \\
\text { longitudinal comparison, it can be } \\
\text { used in the horizontal comparison, } \\
\text { easy to find out the weak link, } \\
\text { provide the basis for the } \\
\text { improvement of evaluation } \\
\text { objects }\end{array}$ & $\begin{array}{l}\text { 1. Different judgments in } \\
\text { consistency within the } \\
\text { effective range structure } \\
\text { inverse matrix, may be } \\
\text { different evaluation results } \\
\text { 2. Using the grade nine point to } \\
\text { index are compared, and the } \\
\text { two easy to make conflict and } \\
\text { chaos of judgment } \\
\text { 3. After by weighted average, } \\
\text { layering, comprehensive, } \\
\text { index weakened }\end{array}$ \\
\hline TOPSIS & $\begin{array}{l}\text { 1. No special requirements on } \\
\text { the sample data } \\
\text { 2. Can make full use of original } \\
\text { data information, tallies with the } \\
\text { actual situation } \\
\text { 3. The advantages and } \\
\text { disadvantages of each evaluation } \\
\text { objects may be sorted }\end{array}$ & $\begin{array}{l}\text { 1. When two evaluation indexes } \\
\text { about the optimal scheme of } \\
\text { object and the worst scheme } \\
\text { attachment symmetry, and } \\
\text { unable to obtain accurate } \\
\text { results } \\
\text { 2. Can only be on the pros and } \\
\text { cons of each evaluation } \\
\text { objects to sort, cannot divide } \\
\text { class management, the } \\
\text { sensitivity is not high }\end{array}$ \\
\hline RSR & $\begin{array}{l}\text { 1. Do not introduce the subjective } \\
\text { variables, it overcomes the defect } \\
\text { of subjective weighting } \\
\text { 2. The comprehensive ability is } \\
\text { strong, can be used as a special } \\
\text { composite indicator for statistical } \\
\text { analysis } \\
\text { 3. Divide class can be sorted, to } \\
\text { eliminate the influence of outliers, } \\
\text { the tiny differences between } \\
\text { display data }\end{array}$ & $\begin{array}{l}\text { 1. Respect to rank in the process } \\
\text { of substitution may lose some } \\
\text { information, lead to use of the } \\
\text { information is not complete } \\
\text { 2. Is not sensitive to outliers }\end{array}$ \\
\hline
\end{tabular}




\section{Conclusion}

Due to the limitation of data types, this article only completed about standard number class index analysis, a standard number class composite index and the rankings, below are involved in the analysis of indicators according to the standard number only class data calculation. Standard quality indexes and value indexes to subsequent analysis.

\section{Acknowledgement}

This research was financially supported by the National standards literature sharing service platform project(25126z-2446-2017).

\section{References}

[1] Kunxiu Ren, The Empirical Study on the Contributions, Comparison and Nature of the National Standards: the Case of Ten Countries, Journal of Shanghai Economic Management College. 13(2015): 3-12.

[2] Chuntian Li, The Evolvement and Significance of the Theory of Standards Classification, China Standardization, 1(2012):53-58.

[3] Gianluca Lax, Giuseppe M. L. Same, A Reputation Model for C2C commerce, Electronic Commerce Research, 08(2008): 193-216.

[4] Huixin Ke, Hao Shen, Statistical Analysis Method in the Investigation, Communication University of China Press, 2005, pp. 193-220.

[5] Michael B. Gordy, A Comparative Anatomy of Credit Risk Models, Board of Govemors of the Federal Reserve System, 12(1998):15-27.

[6] Chuntian Li, Introduction to standardize, China Renmin University Press, 2010, pp.19-20, $110-114$.

[7] Lu JianChang, Liao Jing, E-Commerce Customer Credit Evaluation Based on AHP. Software Engineering and Service Sciences, 6(2010):655-65. 